\title{
Interaction and passion in a PDP community
}

\section{Sue Burkinshaw, Project Lead}

University of Bolton, UK

Communities of Practice are groups of people who share a concern, a set of problems, or a passion about a topic, and who deepen their knowledge and expertise in this area by interacting on an ongoing basis. (Wenger et al., 2002, p.4)

\section{Background}

The National Action Research Network on Researching and Evaluating Personal Development Planning and e-Portfolio Practice was one of eight successful national project bids to be awarded funding for a three year period, through the newly launched Higher Education Academy National Teaching Fellowship project strand in July 2007 (HEA, 2010). The project was relatively ambitious and wide-reaching in that it was a collaborative project involving sixteen Higher Education UK institutions (representative of pre 1992 and post 1992 Universities) and the national educational charity the Centre for Recording of Achievement (CRA, 2010). The sixteen project members were drawn from the membership base of the CRA. The CRA has provided a national practitioner network community since the early 1990's, supporting members in the development and implementation of Personal Development Planning (PDP) initiatives and institutional frameworks across the Higher Education (HE) sector.

In general, the project members of the National Action Research Network (NARN) tended to be PDP practitioners who were institutional leaders for PDP at their University and/or PDP champion(s) within their own institution/faculty/department. Each Institutional member of the collaborative project undertook situated research within their own institution, with the aim to evaluate practice and to offer a contribution to the existing knowledge/research and pedagogies underpinning PDP. The initial outcomes of our members' research is published in this special edition of the Journal of Learning Development in Higher Education 'Researching PDP Practice'. 
Alongside developing a body of scholarly knowledge capable of informing effective implementation of PDP for students, the project sought to develop a community of PDP practitioners who were capable of developing, implementing and learning from ongoing, robust research and evaluation of practice. The key aims of the project were therefore twofold:-

- To advance the understanding of factors that lead to enhanced student learning through the PDP process, and to provide transferable outputs.

- To build the capability and capacity of PDP practitioners as researchers to produce their own research base in relation to PDP and e-Portfolio for students.

\section{Communities of Practice: the NARN model in building research capability and capacity}

At the heart of the project was the development of a community of practice (Lave and Wenger, 1991) where a group of people come together to share common interests and goals, with the aim of sharing information, developing knowledge and developing themselves both personally and professionally.

The first paper in this special edition of the JLDHE is 'Building research capacity in a practitioner community: framing and evaluating the National Action Research Network on researching and evaluating Personal Development Planning (PDP) and e-Portfolio practice' by John Peters (Principal Investigator). He explores the meta-level of the NARN project as a piece of action research on research capacity building within a practitioner community. The research captures and documents the reflective personal developmental journeys of the participants whilst being engaged in the NARN project.

With a national collaborative project of this nature involving sixteen institutions, we adopted a multi-layered and structured approach to organisation, with a leadership team and the formation of three geographical, regional groups (North, Midlands and South). The regional groups were key to the success of the project and the development of the NARN community, thanks to the commitment, contribution and guidance provided by each Regional Lead. The latter made a significant contribution in the building of a supportive community, where members felt they could openly discuss and share their ideas and 
concerns throughout the research journey. They also fostered and developed a community whereby members were able to act as 'critical friends' to each other's research projects.

The Regional Leads' joint paper (see Keenan, Kumar and Hughes in this volume) 'Forming communities of practice' describes the experiences of the three regional groups and how each group developed a unique sense of identity and ways of working. This paper offers an insight into developing communities of practice, identifies a number of characteristics that contribute to their success, and evaluates how the model we adopted served to support our members in undertaking their PDP research journey.

As the project developed over time, one unanticipated outcome was that some member Institutions created 'institutional research teams' to support the NARN project. The University of Bedfordshire project, led by Arti Kumar (Midlands Regional Lead), adopted and implemented the full NARN project model and applied this across the institution to support academics and practitioners to develop their capacity and capability as researchers. This 'mini' NARN was established as the Action Research Consortium (ARC) which saw twelve staff successfully complete action research projects. In her paper, 'Turning the NARN into an ARC at the University of Bedfordshire - some reflections and comparisons' Arti Kumar provides an honest and critical account in which she explores from a management perspective how the ARC framework supported practitioners engaged in action research.

It is through the strength of the community of practice model that all NARN members have:

- Remained fully committed to the aims and objectives of the project throughout its life.

- Felt confident and capable of undertaking research related to PDP.

- Taken up opportunities to present their research at a number of national and international conferences.

- Taken up the opportunity to publish their research in a refereed journal of international standing. 


\section{Personal Development Planning (PDP)}

Personal Development Planning is defined as:

A structured and supported process undertaken by an individual to reflect upon their own learning, performance and/or achievement and to plan for their personal, educational and career development. (QAA, 2009, p.1)

The NTFS NARN project aimed to address sector-wide issues concerned with the effective implementation of PDP practice and to respond to repeated calls for more robust evaluation of PDP in the UK (QAA, 2001; Gough et al., 2003; Burgess, 2004; Clegg, 2004). The paper authored by Strivens and Ward provides context for this special edition, exploring what is meant by PDP and tracing how far the sector has come in its implementation, including the introduction of new technologies to support the PDP process over the last five years.

Hughes et al., in 'Situated Personal Development Planning' examine local PDP practices across four academic programmes of study. Their paper explores how diverse forms of PDP curriculum have evolved and been developed within an institutional framework. They reassert the importance of local contexts and cultures and their influence in shaping PDP practices. They argue that we should worry less about identifying best practice pedagogy of PDP and pay greater attention to the range of social influences on curriculum design to develop a greater understanding of PDP, its effectiveness and contribution to learner development. Early research around the implementation of PDP, suggested an emergence of a multiplicity of meaning and function(s) with a variety of distinct practices and interpretations being adopted across the HE sector (Clegg, 2004). Hughes et al. point to the value of diversity and of the situated nature of PDP practices.

A number of our members' papers in the journal, relate to research and findings around student perceptions of the meaning and value of PDP processes and practices. Davey and Lumsden in 'From cats to roller-coasters: creative use of posters to explore students' perceptions of PDP' explore students' perceptions of PDP through textual analysis and the use of posters in a longitudinal two year study. The paper by Jankowska, 'Taking Concept Mapping (CM) forward with socially mediated structured approaches', also explored 
meaning by asking postgraduate students the question: what does Personal Development Planning mean to you?

The perceptions and engagement of staff in the success of PDP approaches and practices is a prevalent theme throughout papers in this journal. Powell explores staff perceptions of the value of PDP in 'Useful or just another fad? Staff perceptions of Personal Development Planning'. Her research found that many staff valued the PDP process but that many viewed the individual elements or component parts of PDP more positively than PDP itself. This resonates with other papers where there is a suggestion that the terminology of PDP is not helpful (Davey and Lumsden; Rowe; Hughes et al.).

'How do different models of PDP influence the embedding of e-Portfolios?' asks Frith. She investigated a number of programmes and disciplines in relation to PDP practices and how these relate to characteristics of PDP which focus upon a model defined by Clegg and Bradley (2006), describing its use in three contexts: professional, academic and employment. This paper acts as a useful introduction to Clegg and Bradley's model which is cited in a number of other papers in this collection e.g. Professional (Riddell and Bates); Employment (Rowe; Wilson-Medhurst and Turner) and Academic (Davey and Lumsden).

Wilson-Medhurst and Turner in 'An evaluation of the impact of e-Portfolio supported pedagogic processes on students' reflective capacity' explore undergraduate modules which have an explicit focus on employability. The paper explores how an e-Portfolio tool can support students in their learning development and asks the question: what are the elements that support and encourage the reflective capacity of students?

Savory et al. in 'The role of Personal Development Planning (PDP) for employer sponsored students - an exploration of how PDP learning activities can support CPD and workforce development requirements' build on work by Clegg and Bradley (2006) and develop the employability model further. They discuss and highlight how PDP learning activities can support the appraisal processes within the workplace to support workforce development and organisational performance. In 'What role can PDP play in identity development and confidence building in non-traditional students?' Buckley explores how an online PDP module can serve to support the work-based learner through transition, engagement and achievement. 
The role of the personal tutor in PDP is a theme shared by three of the papers in this journal. Rowe, in 'Evaluating a new e-PDP tool and its relationship with personal tutoring', states that the nature of the relationship between the student and the individual tutor is key to the PDP process. This is supported in 'The role of the personal tutor in a curricula approach to Personal Development Planning' by Riddell and Bates, which gives evidence that 'relationship-building' between the personal tutor and the student is critical to enabling effective support and learning development. Finally, Raiker's paper, 'An investigation into the undergraduate dissertation tutorial as a Personal Development Planning (PDP) process to support learner development' demonstrates that the tutorial appears to be effective as a PDP process in enabling learner development in meeting the needs of some students if not all. All three of these papers evidence the positive impact that the curriculum model of student support (Earwaker, 1992) can have in relation to PDP and learner development. They suggest that the personal tutor system is a primary vehicle by which to encourage students to reflect not only on academic progress but also more holistically about their learning in context.

In their overview of the development of PDP at the beginning of this journal, Strivens and Ward point to a need to further our understanding of e-Portfolio practice. Over half of the NTFS NARN members in their research studies review PDP which is linked to e-Portfolio practice and/or technology. In this we offer a contribution and additional insight into the impact and effective use of e-Portfolios to support a new generation of learners.

Symonds presents us with a study 'Evaluating an e-Portfolio implementation with early adopters using Appreciative Inquiry' which sought staff and student perceptions of an institution-wide e-Portfolio system. These research findings highlight factors which influence effective e-Portfolio learning, relating to tutor engagement; the need for technical and pedagogical support; and the embedding of the e-Portfolio in the curriculum. Lawton and Purnell also undertook an institution-wide study from a number of perspectives: the evaluation of a university-wide e-Portfolio; the facilitating and inhibiting factors affecting the sustainability and scale of e-Portfolio based PDP across an institution; and factors that contribute to engagement with PDP.

'Blogs and e-Portfolios: can they support reflection, evidencing and dialogue in teacher training?' by Cotterill et al. offers us a debate on the level of structure required in ePortfolios and blogs for vocational subjects, and factors relating to engagement and 
concurrent use of formal/institutional social networking sites. Moule and Rhemahn in 'Student experience with e-Portfolio: exploring the roles of trust and creativity' explore the perceived added value of creativity and play that e-Portfolios can potentially offer. They also raise the emotional dimension of' trust with respect to the use of e-Portfolios and potential barriers to the engagement with e-Portfolio.

The range, variety and complexity of PDP is evident across all of these papers by the NTFS NARN members. This reflects Clegg's (2004) research where PDP processes were seen to have relevance for improving students' understanding of how they are learning; enabling students to reflect critically; helping students become independent learners; encouraging students to build upon their academic work; extra-curricula activities; career opportunities and general employability. Although our members' selection of their research areas in itself evidences a trend towards the 'Employability' model of PDP (Clegg and Bradley, 2006), it is nonetheless clear that there is support for the utilisation of e-Portfolio and other electronic tools to support a broader interpretation of learning development. Strivens and Ward suggest that further research into the impact and effective use of ePortfolios for such purposes would be welcome.

The NTFS NARN set out to develop a body of scholarly knowledge capable of informing more effective implementation of PDP for students. Each member's research contribution reveals a rich picture of the experience of PDP within different HE situations and with different groups of learners. These pictures serve to illuminate how engagement with varying PDP practices and processes can enhance the overall student learning experience. This special edition of the Journal of Learning Development in Higher Education has provided us with a welcome and valuable opportunity to share our journey in the development of the HEA NTFS project; share the approaches we have taken to building a research community; and to proudly present our members' research in PDP. We are grateful to John Hilsdon and Andy Hagyard, JLDHE editors, for providing us with this opportunity, and for their support and guidance to our membership community in the final leg of the research journey - writing for publication.

Throughout the research project journey, it has been evident that the motivation and commitment of all our members is in their endeavour to make a positive difference to learning development and the learning environment. We hope that the research that we have presented in this journal will stimulate discussion and debate, serve to inform and 
enhance PDP processes, and encourage others to participate in and/or develop new research communities of practice.

On a personal note, it has been a pleasure and a privilege to lead on this national project, to share the project research journey with all the NARN members and to have the opportunity to work with and be inspired by such enthusiastic individuals! Their passion and their interaction through the broader learning development community (including through the pages of the JLDHE) shows real dedication and commitment to improving students' experiences of learning through PDP in HE. Finally, we are all indebted to Dr. John Peters (University of Worcester) who conceived of the idea to create the NARN in PDP and e-Portfolio Practice, without which none of this would have happened.

\section{References}

Burgess, R. (2004) Measuring and recording student achievement: report of the Scoping Group. Universities UK. Available at:

http://www.universitiesuk.ac.uk/Publications/Documents/measuringachievement.pdf (Accessed: 8 November 2010).

Clegg, S. (2004) 'Critical readings: progress files and the production of the autonomous learner', Teaching in Higher Education, 9(3), pp. 287-298.

Clegg, S. and Bradley, S. (2006) 'The implementation of progress files in higher education: reflection as national policy', Higher Education, 51(4), pp.465-486.

CRA (2010) The Centre for Recording Achievement. Available at: http://www.recordingachievement.org/ (Accessed: 07 November 2010).

Earwaker, J. (1992) Helping and supporting students. Milton Keynes: Open University Press. 
Gough, D.A., Kiwan, D., Sutcliffe, K., Simpson, D. and Houghton, N. (2003) A systematic map and synthesis review of the effectiveness of personal development planning for improving student learning. London: EPPI-Centre, Social Science Research Unit, Institute of Education, University of London. Available at: http://eppi.ioe.ac.uk/cms/Default.aspx?tabid=309 (Accessed: 8 November 2010).

Higher Education Academy (2010) National Teaching Fellowship Scheme Projects. Available at:

http://www.heacademy.ac.uk/ourwork/supportingindividuals/ntfs/ntfsprojects (Accessed: 8 November 2010).

Lave, J. and Wenger, E. (1991) Situated learning: legitimate peripheral participation (learning in doing: social, cognitive and computational perspectives). Cambridge: Cambridge University Press.

QAA (2001) Guidelines for HE progress files. Available at:

http://www.qaa.ac.uk/academicinfrastructure/progressFiles/guidelines/progfile2001. asp (Accessed: 3 November 2010).

QAA, (2009) Personal development planning: guidance for institutional policy and practice in higher education. Available at:

http://www.qaa.ac.uk/academicinfrastructure/progressFiles/guidelines/PDP/PDPgui de.pdf (Accessed: 8 November 2010).

Wenger, E., McDermott, R. and Snyder, W.M. (2002) Cultivating communities of practice. Boston: Harvard Business School Press.

\section{Author details}

Sue Burkinshaw is Head of Learning Enhancement and Professional Development and a University Learning and Teaching Fellow at the University of Bolton. She was the Project Leader for the Higher Education Academy (HEA), National Teaching Fellowships, 'National Action Research Network on Researching and Evaluating Personal Development Planning and e-Portfolio Practice' project. Sue also led the 
strategic development and implementation of the Personal Development Planning for students framework at the University of Bolton. She is a Fellow of the Higher Education Academy and a Chartered member of the Chartered Institute of Personnel and Development. Sue is also a member of the Board of Trustees for the Centre for Recording Achievement. 